\title{
APPLICATION OF THE METHOD OF FACTOR ANALYSIS IN THE ASSESSMENT OF THE TECHNICAL CONDITION OF THE HARD COVER AIRPORT
}

\author{
Vladimir Malikov ${ }^{1}$ Bogdan Bojarchuk ${ }^{2}$, Andrii Bieliatynskyi ${ }^{3}$, Iryna Klymenko ${ }^{4}$, \\ Vasyl Orzheshkovskyi ${ }^{5}$, Ludmila Orzheshkovska ${ }^{6}$ \\ ${ }^{1,2}$ Lutsk National technical university, 75 Lvivska, st. Lutsk 43018, Ukraine \\ ${ }^{3}$ National Aviation University Kiev, Ukraine, Kosmonavta Komarova ave. 1 \\ ${ }^{4}$ National Transport University, Kiev, Ukraine, 1, Suvorova st. \\ ${ }^{5,6}$ P.L.Shupik National Medical Academy of Post-Graduate EducationKiev, Ukraine, Dorogozhytska st. 9 \\ E-mails: ${ }^{1}$ vladmalikov@yandex.ru; ${ }^{3}$ beljatynskij@mail.ru; ${ }^{4}$ kirak76@mail.ru; ${ }^{5}$ Vasily_O@voliacable.com
}

\begin{abstract}
The results of the experiments and presented results of their statistical analysis is proposed to use the results of factor analysis to evaluate the technical condition of the hard cover. Through the use of computer programs SPSS Staistics 17 and MS Excel data obtained were processed and built the necessary graphics. Established uneven depressions are the applied experimental load in the direction of the landing aircraft. The application of factor analysis techniques can allow identify areas of reduced carrying capacity of coverage in certain parts of the band. The final decision on the state covering the runway can be formulated with additional studies cover bands in these areas.
\end{abstract}

Keywords: Airfield pavements, slabs, method of factor analysis, correlation coefficient deflections, curve approximation, deflections of plates.

\section{Introduction}

Airfield pavements are design, the load and impact of aircraft, operational and environmental factors and meeting the requirements for safety. One of the essential qualities of airfield pavements, determining the extent of such security is their strength, stability and durability, especially in complex hydrogeological conditions. In the operation of airfield pavements are affected by the load of the wheel supports aircraft. Features of these loads are taken into account in the calculation and design of various types of coatings. Reliability and durability of airfield pavements are largely determined by the design provisions built into the project, the quality of the materials used by the construction technology, the adequacy of computational models of "cover-base" the real picture, operating conditions, and the volume of external factors to consider when designing a (temperature outside environment, moisture, hydrology, seismology, relief, etc.). In accordance with the laws of variation of these external factors create stress and strain fields in the elements of airfield pavements. Natural climatic conditions (effects) are an essential and integral part of the external loads, which, in the end, and determines the values of temperature and humidity of strains and stresses in the airfield pavement. 1992):

Problems with airfield pavement (Glushkov et al.

- Peeling-surface due to freeze thaw cycles, and mechanical loads;

- Potholes and shells from the dynamic loads;

- Cracks (through) due to the impact of sulphates;
- Cracks (through) due to alkali-silica reaction;

- Erosion-surfaces in hot climates in the sands;

- Separation top coat and shrinkage cracks (cracks) due to concrete at high temperatures and improper care. These cracks have properties gradually increase in depth and length, and often branch out in different directions;

- Separation top coat because exposure to de-icing compounds and salts;

- Chipped edges of plates and the destruction of joints due to freeze / thaw cycles, and mechanical loads;

- Separation top coat because exposure to fuel oil or chemicals;

- Destruction of plates from power loads;

- The ragged-in seams and cracks due to the rise of plates;

- Drawdowns, and breaks plates bearing capacity due to the loss of a base or soil;

- Destruction-joint filler due to the low thermal stability of the aggregate.

In order to get information about Artificial takeoff runway (runway) airport in Lutsk was conducted with metering deflection plates precast concrete coating when exposed to static, degreeal load. Runway has parameters $2550 \times 44 \mathrm{~m}$ and represents a prefabricated concrete slabs coated with ПАГ-18 top row and ПАГ-14 bottom with a layer of cement-sand mixture $5 \mathrm{~cm}$, besides two extreme longitudinal rows enclosed in a row slabs ПАГ-18.

\section{Experimental part}

According to the chosen method of measurement were conducted using a hard metal punch (metal disk 
diameter $-44.0 \mathrm{~cm}$ and $2 \mathrm{~cm}$ thick) installed in the center of the plate cover, hydraulic jack with max capacity $500 \mathrm{kN}$. As low applied load frame trawl ЧМЗАП-5208 and 7 plates ПАГ-14. Deflections measurements were carried out using 2 - oh time sensor type (МИГ-1 point value of $1 \mathrm{mkm}$ ), which are located on a metal beam (channel number 12) length of $2.6 \mathrm{~m}$ for leaning outside cover plate airfield to be loaded rice 1 . To fix the value of stress was used a standard dynamometer ДОС-100 scale load of $1000 \mathrm{kN}$. For additional control deflections of the load was applied leveling „Sokia“ x21, which were shot from outside the band.

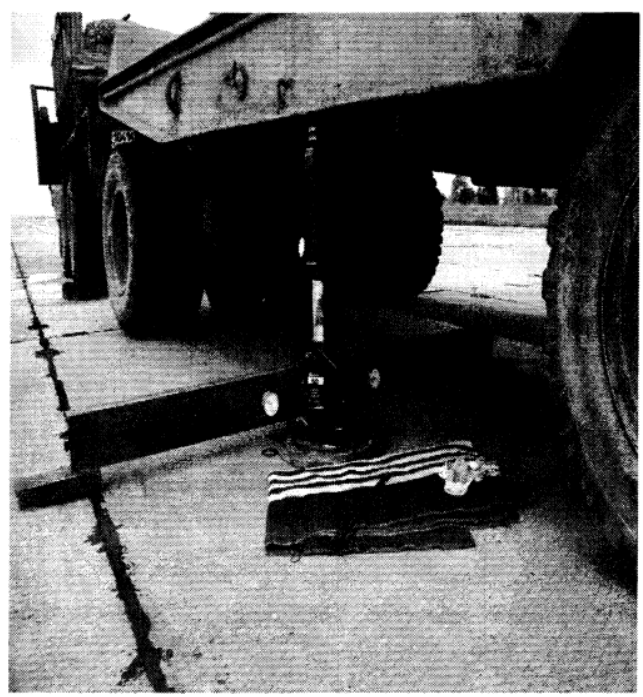

Fig. 1. Location of instruments for the experiment on runway

All measurements were conducted on a 32-step plates with 10 plates $(60 \mathrm{~m})$ with 4 cookers are cookers extreme strip series. Direction measurements (numbered plates) coincides with the movement of the aircraft (aircraft) while landing, ie number 1 center plate located at a distance of $27 \mathrm{~m}$ from the beginning of the band on its longitudinal axis. The total length of $1920 \mathrm{~m}$ experimental plots

Overall results of measurements are presented in dotted curves in Fig. 2. As we have seen quite a significant scatter of results.

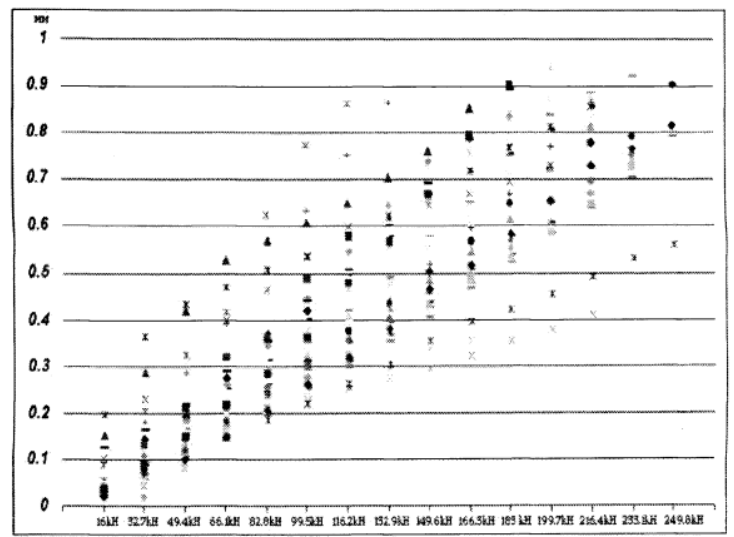

Fig. 2. Bitmap schedule overall results of measurements
A preliminary analysis of the mean values of deflections are shown in Figure 3 - blue broken line and approximated by a polynomial - red line. Moreover, the plate number $11,29,30,31$ (ПАГ plates - 18 in a single layer) were delivered at the end of the sample, where we see an increase averages.

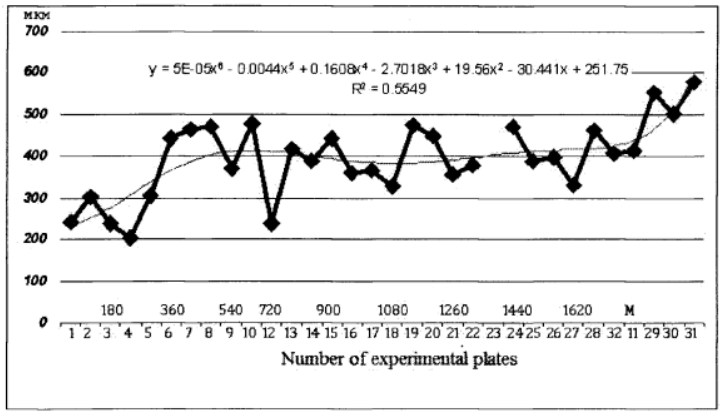

Fig. 3. Schedule a preliminary analysis of the average values of deflection plates

To reduce the number of variables and determine the structure of the relationship between the results of researches apply factor analysis of research results deflections slabs of runway action degreeal pilot workload. The results deflections runway slabs were processed using the program SPSS Staistics 17.

As a result of the data was provided with one main factor of influence to sampling variance, which explains more than $98 \%$ deviation measurements deflections of plates (Table 1), it is obvious - the action experimentally simulated load.

Table 1. Processed results deflections slabs runway

\begin{tabular}{|c|c|c|c|c|c|c|}
\hline \multirow[b]{2}{*}{ 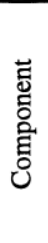 } & \multicolumn{3}{|c|}{ Initial eigenvalues } & \multicolumn{3}{|c|}{$\begin{array}{c}\text { Sum of squared loadings } \\
\text { removal }\end{array}$} \\
\hline & 丞 & 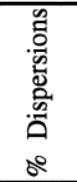 & 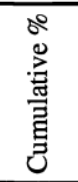 & 졍 & 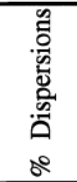 & 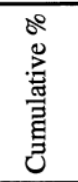 \\
\hline 1 & 31.44 & 98.26 & 98.26 & 31.44 & 98.26 & 98.26 \\
\hline 2 & .385 & 1.20 & 99.47 & .385 & 1.20 & 99.47 \\
\hline 3 & .097 & .303 & 99.77 & .097 & .303 & 99.77 \\
\hline 4 & .034 & .105 & 99.87 & .034 & .105 & 99.87 \\
\hline 5 & .024 & .074 & 99.95 & .024 & .074 & 99.95 \\
\hline 6 & .015 & .047 & 100.0 & .015 & .047 & 100.0 \\
\hline 7 & .000 & .000 & 100.0 & .000 & .000 & 100.0 \\
\hline 8 & .000 & .000 & 100.0 & .000 & .000 & 100.0 \\
\hline 9 & .000 & .000 & 100.0 & .000 & .000 & 100.0 \\
\hline 10 & .000 & .000 & 100.0 & .000 & .000 & 100.0 \\
\hline$\ldots$ & $\ldots$ & $\ldots$ & $\ldots$ & $\ldots$ & $\ldots$ & $\ldots$ \\
\hline 30 & .000 & .000 & 100.0 & .000 & .000 & 100.0 \\
\hline 31 & .000 & .000 & 100.0 & .000 & .000 & 100.0 \\
\hline 32 & .000 & .000 & 100.0 & .000 & .000 & 100.0 \\
\hline
\end{tabular}

Missed lines $11 \ldots 29$ similar results of the initial and final values.

To determine the capacity of each communication factors identified in accordance with the experimental load degreeal apply mathematical method Varymaks orthogonal rotation with Kaiser normalization. The results are presented in table 2 . 
Table 2. Dependence identified factors degreeal experimental load

\begin{tabular}{|c|c|c|}
\hline \multirow{2}{*}{ Degrees load } & \multicolumn{2}{|c|}{ Component } \\
\cline { 2 - 3 } & 1 & 2 \\
\hline $16 \mathrm{kH}$ & -.402 & .916 \\
\hline $32,7 \mathrm{kH}$ & -.113 & .699 \\
\hline $49.4 \mathrm{kH}$ & .312 & .932 \\
\hline $66.1 \mathrm{kH}$ & .783 & .620 \\
\hline $82.8 \mathrm{kH}$ & .956 & .273 \\
\hline $99.5 \mathrm{kH}$ & .968 & .070 \\
\hline $116.2 \mathrm{kH}$ & .996 & .064 \\
\hline $132.9 \mathrm{kH}$ & .998 & -.056 \\
\hline $149.6 \mathrm{kH}$ & .965 & -.173 \\
\hline $166.3 \mathrm{kH}$ & .983 & -.170 \\
\hline $183 \mathrm{kH}$ & .980 & -.194 \\
\hline $199.7 \mathrm{kH}$ & .970 & -.241 \\
\hline $216.4 \mathrm{kH}$ & .937 & -.334 \\
\hline $233.1 \mathrm{kH}$ & .893 & -.448 \\
\hline $249.8 \mathrm{kH}$ & .693 & -.695 \\
\hline & & \\
\hline & & \\
\hline & &
\end{tabular}

According to the obtained coefficients are building their dependence on action degreeal static load and try to approximate. The biggest factor approximation to accuracy obtained curves gives the sixth degree polynomial.

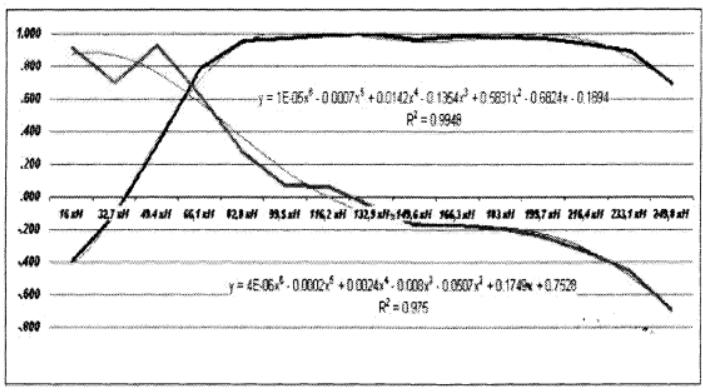

Fig. 4. Koefitsientov depending on the action of static load

Interpretation of these two factors may be, in our opinion, a number 1 - the resistance of the soil array (joint work and foundations pidstelyayuchy soil layers), series 2 - the resistance of pavement (with \slab strip).

Were obtained correlation coefficients of each experimental deflections of plates of degreeal load as the main factor action based on the results of the method of selection of principal components (Table 3). Density connection powerful enough, but there are changes in the correlation coefficient for long strip. To identify the nature of change using MS Excel was built graph that displays the distribution coefficient of correlation in length (blue broken line), which was approximated by a polynomial curve of sixth degree range (red curve) Fig. 3 .

Results deflections extreme series boards have been moved to the end of Table 2, the graph (blue broken line) shows decrease in correlation coefficient plate number $11,29,30,31$. We see a drop in density connection between exposure to stress and deflection plates in the terminal phase zone where slabs PAG-18 invested in a single layer. Plate number 23 is excluded from the sample due to the minimum value of the values for plates in two layers.
Table 3. The correlation coefficients of each experimental deflections of plates of degreeal load

\begin{tabular}{|c|c|c|c|}
\hline \multicolumn{2}{|c|}{ Plates ПАГ-18 in a single layer } & 11 & 0.998 \\
\cline { 3 - 4 } \multicolumn{2}{|c|}{} & 29 & 0.965 \\
\cline { 3 - 4 } & 30 & 0.985 \\
\cline { 3 - 4 } & 31 & 0.904 \\
\hline 5 & 0.991 & 20 & 0.998 \\
\hline 6 & 0.999 & 21 & 1.000 \\
\hline 7 & 1.000 & 22 & 0.999 \\
\hline 8 & 0.997 & 23 & 0.975 \\
\hline 9 & 0.995 & 24 & 0.995 \\
\hline 10 & 0.999 & 25 & 0.996 \\
\hline 12 & 0.992 & 26 & 0.997 \\
\hline 13 & 0.992 & 27 & 0.993 \\
\hline 14 & 0.991 & 28 & 0.989 \\
\hline 15 & 0.993 & 32 & 0.996 \\
\hline
\end{tabular}

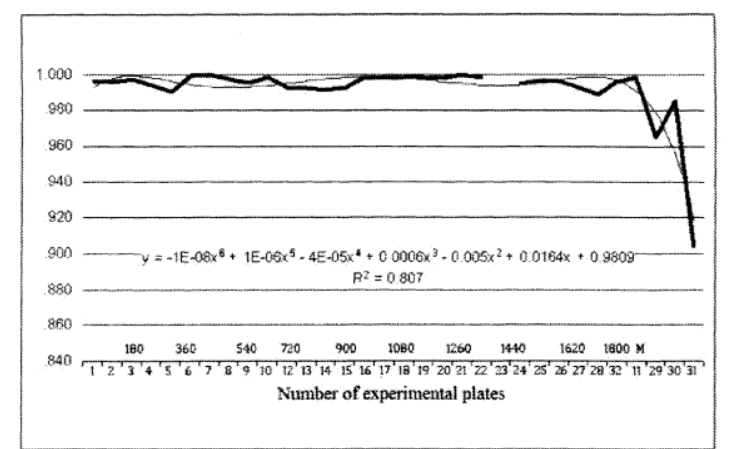

Fig. 5. Figure decreasing correlation coefficient boards No $11,29,30,31$

To solve the problem of character changes the relationship between the influence of the experimental load deflection plates and strips for her length, excluding slabs extreme series were built broken (blue broken line), reflecting the dependence of the correlation coefficient along the length of the band and approximated by analogy with Fig. 3 (red curve).

Curve approximation has a distinct character that suggests the idea of uneven depressions are the applied experimental load in the direction of landing aircraft (PS) Figure 4.

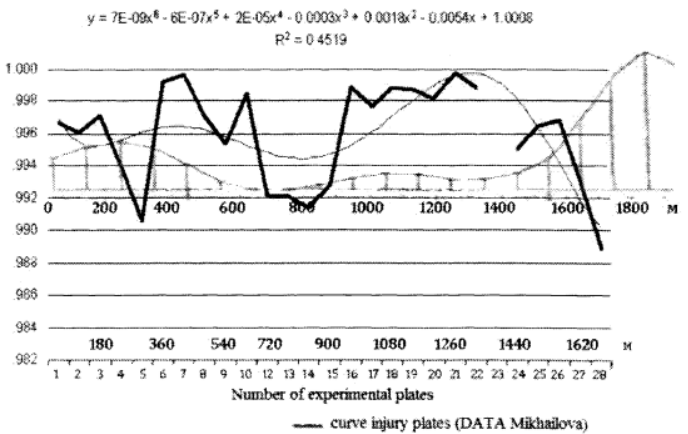

Fig. 6. Curves damage concrete slabs

Question decrease of the correlation coefficient try to interpret as a reduction in carrying capacity of slabs. Justification of this statement may be based on a comparison of the distribution of concrete pavement slabs with 
damage along the length (green curve according to $\mathrm{A}$. Mikhailov) (Glushkov et al. 1992: 326) of the curve approximation (red line) from the data obtained.

\section{Conclusions}

Based on the above assumptions and focusing on the character of the dependences should be noted critical line of work clothing runway $-150 \ldots 180 \mathrm{kN}(\mathrm{PSN} \approx 30 \ldots$ 36) after which goes characterized by falling on two graphs. So you can set the maximum runway capacity at which you can expect reliable operation at limited weight of the airplane used. So application of factor analysis allows to select areas with decreasing bearing capacity coverage in areas up to $300 \mathrm{~m}$ strip from the beginning band, the section $600 \ldots 1100 \mathrm{~m}$ and $1500 \mathrm{~m}$ to the end of the experimental plots for a given runway. It is known that the water-base thermal conditions change constantly throughout the year: in summer it dries up during normal operation of the drainage system in the fall and spring, on the contrary, pereuvlazhnyaetsya in winter - frozen. Moisture enters the subgrade surfaces in several ways: rising from the level of the water table through the capillaries, the film covering the soil particles, in the form of water vapor, as well as penetrating the surface of concrete slabs through joints and cracks, and on the surface of the asphalt - also through the material coverage in violation of its structure. The main source of excess moisture of soil bases coating is water, which is pulled to the cover of the underlying layers under the influence of temperature gradients. In winter, the freezing reason is an increase in its resistance to airborne loads, increased load-bearing capacity. In periods of thaw and frost weak when freezing is suspended under the cover of intense moisture accumulates (Kulchickij et al. 2002). This process is particularly noticeable in the spring when thawing soil at the base of the coating. Moistening the soil lowers its resistance to external loads. Thus, the strength of the soil at the base of coatings varies throughout the year depending on changes in their moisture content, which in turn is related to the temperature. Therefore, the definition of heat and state grounds airfield surfaces is an important problem, and its solution has always paid great attention. The adoption of a final decision on the operation of the runway with the proposed classification requires a number of additional studies cover band and surveys with regard to temperature and humidity regime underlying soils.

\section{References:}

Glushkov, G.; Babkov V.; Trigoni V. 1992. Survey and design of airfields: Textbook for Universities. 2-e edition. - Mосква: Transport. $432 \mathrm{c}$.

Kulchickij, V.; Makagonov, V.; Vasilev, N.; Checov, A.; Romankov, N. 2002. Airfield pavements. The modern view. Mocква: Physical and mathematical literature. $528 \mathrm{c}$. ISBN 5-9221-0215-X. 